\title{
The Nigerian juvenile justice system: from warehouse to uncertain quest for appropriate youth mental health service model
}

\author{
O. Atilola, ${ }^{1}$ G. Abiri ${ }^{2}$ and B. Ola ${ }^{1}$
}

${ }^{1}$ Department of Behavioural Medicine, Lagos State University College of Medicine Ikeja, Lagos, Nigeria; email draromedics@ yahoo.com

${ }^{2}$ Child and Adolescent Unit, Federal Neuro-psychiatric Hospital Yaba, Lagos, Nigeria

Conflicts of interest. None.

\section{doi:10.1192/bji.2017.37}

(c) The Authors 2018. This is an Open Access article, distributed under the terms of the Creative Commons

Attribution-NonCommercial-NoD erivatives licence (http://creativecommons.org/licenses/by-nc-nd/ $4.0 /$ ), which permits non$4.0 /)$, which permits non-
commercial re-use, distribution, and reproduction in any medium, provided the original work is unaltered and is properly cited. The written permission of Cambridge University Press must be obtained for commercial re-use or in order to create a derivative work.
Mental health service provision for youth within the juvenile justice system remains a topic of contemporary global discourse. To bring perspectives from under-resourced regions, we examine the current limitations of some globalised models for mental health services within the juvenile justice system in Nigeria. The important multi-systemic steps needed to reposition the system for modern mental health promotion and services are highlighted.

\section{Background}

Although currently available data suggest a recent global decline, the total population of youth within the juvenile justice system worldwide is still very high (Penal Reform International, 2015). Among this population, systematic reviews have established a high prevalence of mental and behavioural disorders (Fazel et al, 2008). As a result of this observation, the need for and approaches to mental health services remains a topic of contemporary discourse in juvenile justice administration around the globe (Kates et al, 2014). Dominant among the themes of this discourse is the ongoing debate on the appropriate model for providing mental health services for youth while in detention (Alcorn, 2014). This discourse is, however, largely shaped by the current state of development of the juvenile justice system in high-income countries, as well as by the globalised view of availability and utilisation of youth mental health services.

There are differences across different regions of the world and in the demographic and criminal profiles of juvenile justice populations, as well as in the sophistication of the systems put in place to address their needs. Owing to cultural and racial differences in the perception and conceptualisation of mental and behavioural disorders, differences have also been observed in mental health service utilisation among incarcerated youth (Rawal et al, 2004). These potential regional differences in the demographics, service needs and availability of service are too important to be ignored in the global discourse around mental health service models for detained youth. Otherwise, important nuances which can ensure that a truly inclusive and global consensus emerges from the current debate will be missed.

In this report, as a prototype for sub-Saharan Africa, we examine the peculiarities of population and operations of the Nigerian youth correctional system. We further examine how such peculiarities limit the applicability of some currently suggested globalised models for mental health services for juvenile justice-involved youth in the country.

\section{The Nigerian juvenile justice system:} unique in its own unsettling way

In the 2009 report of the United Nations (UN) Committee on the Rights of the Child, the Nigerian juvenile justice system was described as being in a state of 'crisis' (UN Committee on the Rights of the Child, 2009). This crisis is still ongoing and is currently driven by myriads of operational, resource, and capacity challenges within the system. Key among the factors maintaining the crisis is lack of community-based diversion programmes within the system, as already elaborated elsewhere (Atilola, 2013). As such, there is no alternative form of disposal of youth offenders other than incarceration. It is therefore not unusual to find status offenders (such as youth arrested for loitering during school hours or for violating night curfew) and minor offenders (such as those arrested for nonaggressive stealing, non-violent property trespass, or hawking wares on the streets) as residents of youth correctional institutions in Nigeria (Atilola, 2014; Atilola et al, 2017). The majority of these youth are from poor neighbourhoods and have survived a variety of childhood traumas and adversity. In other regions with betterdeveloped systems, minor and status offenders are diverted to non-incarcerating community programmes.

In addition, despite an estimated youth population of about 50 million, there are only three federal-run youth correctional institutions established by statute in Nigeria, with a combined capacity of about 600 beds. As expected, these institutions are overcrowded, overstretched and unable to accommodate a significant proportion of offending youth. As a stop-gap, social welfare institutions in the states of the federation often serve as makeshift youth correctional facilities 
for young offenders, in addition to their primary function as a place of refuge for abused and neglected youth. This situation has deepened the crisis in the Nigerian juvenile justice system, owing to offenders and victims having to share the same facilities and administrative procedures, with attendant grave ethical and human rights concerns. This sort of situation is no longer a challenge in most high-income regions of the world, as the youth correctional and social welfare systems are distinct and separated.

In essence, the Nigerian youth correctional system is peculiar in that, unlike in other higherincome jurisdictions, it is an amalgam of the social welfare and youth correctional systems, has a high proportion of status and minor offenders compared with serious offenders, and is often overcrowded.

\section{A warehouse for youth mental and behavioural disorder}

As is the case elsewhere, several studies have documented a high prevalence of ongoing mental and behavioural disorders among juvenile justice populations in Nigeria. Compared with a matched sample of non-incarcerated adolescents, Atilola found a higher prevalence $(23 v .63 \% ; P<0.001)$ of ongoing mental and behavioural disorders, such as anxiety, depression and disruptive behaviour disorders, among incarcerated adolescents in Ibadan (Atilola, 2012). Another recent study documented a prevalence of up to $44 \%$ of psychiatric morbidity among residents of some youth correctional facilities in Lagos (Atilola et al, 2017). Pre-incarceration psychosocial problems such as disrupted families, poverty, homelessness, exposure to traumatic events and other childhood adversity were also common among residents of youth correctional facilities in the country (Atilola, 2012; Atilola, 2014; Atilola et al, 2017). Interestingly, there are many similarities in the prevalence and nature of psychiatric morbidity and psychosocial problems among the subpopulations of youth irrespective of whether they are in 'custody' as victims or offenders (Atilola, 2014). Therefore, even when they are admitted to the institutions under a different categorisation, psychiatric and psychosocial morbidity is a fact of life for youth within the peculiar youth administration system in Nigeria.

Despite a high prevalence of ongoing psychiatric and psychosocial problems among residents of Nigeria's youth correctional systems, audits have documented a stark lack of mental health policy, strategy and service provision (Atilola et al, 2017). Most of the youth correctional facilities in Nigeria are also poorly maintained and lack resources for mental health promotion (Atilola, 2014; Atilola et al, 2017). Therefore, young people who are often in the middle of a psychosocial or mental health crisis are often remanded in poorly resourced and ill-maintained institutions without any framework for mental health assessment, promotion or services. In other words, from a mental health perspective, the Nigerian juvenile justice system at present is more of a warehouse where troubled and troubling youth are kept without addressing their psychosocial and mental health needs.

\section{The uncertain quest for a contextualised mental health service model}

Globally, there is a realisation that youth correctional settings are never the most auspicious places for mental health promotion or services (Alcorn, 2014). This has led to a growing adoption of community-based pre-emptive mental health services as a form of diversion, especially for at-risk youth and those who are status or minor offenders (Alcorn, 2014; Kates et al, 2014). This paradigm shift is even more urgent in Nigeria, where a large proportion of arrestees are status or minor offenders, and available facilities are lacking in standard mental health promotion or services (Atilola, 2014). A potential facilitator for the diversion model in Nigeria is the pre-existing presence, however nominally, of social welfare structures (such as the Family Support Unit, Human Integration Department and School Social Service) within communities in Nigeria (Atilola et al, 2017). These are potential platforms on which community-based mental health diversion programmes can be built. A limitation of this approach, however, is the foundational absence of diversion philosophy within the Nigerian juvenile justice establishment, which has been historically anchored in punitive incarceration (Atilola, 2013). Moreover, there is currently a severe dearth of community-based youth mental health services within the country (Robertson et al, 2010), from which such programmes can take root.

In the absence of community diversion, an alternative is to set up mental health services within youth correctional facilities. This can be in the form of an outpost of public mental health institutions or driven by trained staff of the youth correctional system as a form of task-shifting approach. The former is specialist-driven and, as such, standardised. Unfortunately, youth mental health professionals in Nigeria are extremely few and severely over-burdened (Robertson et al, 2010). Therefore, such a model has major operational limitations and is hardly feasible or scalable. This is more so in view of cost considerations and the wide disparities in the regional spread of the scarce youth mental health services in the country. Equally concerning is the risk of explosion in the number of inappropriate placements in youth correctional facilities of nonoffending youth who have mental or behavioural disorders, when specialist mental health services are perceived to be available in such institutions.

The task-shifting approach is thought to be the global direction for mental health services in resource-constrained regions such as Nigeria (Petersen et al, 2012). In the context of youth 
correctional system in Nigeria, it entails that operational staff (social workers and probation-officers) are trained to screen for, identify and deliver psychosocial and psychological interventions for mental and behavioural disorders. This model is pragmatic, as it utilises resources within the youth correctional system. It is also cheaper and more sustainable, as service can be integrated within the normal work schedules of staff. It is feasible in any region of the country where there is a youth facility. Unfortunately, social workers and probation-officers in youth correctional facilities in Nigeria are equally over-burdened, with low staff/ward ratios at present. An ongoing needs assessment showed that only 25 trained social workers or probation officers were working in facilities with a combined capacity of over 300 residents (Atilola et al, 2017). Most of these staff lacked any form of prior exposure or training in psychosocial assessment or intervention which could be built upon. The task-shifting approach, therefore, may equally face potential operational limitations. It is also left to be seen how these workers can combine the role of instilling discipline within the facility on the one hand, with the needed therapeutic alliance for effective psychological intervention on the other hand.

\section{Conclusions and moving forward}

There are sociodemographic and operational challenges which limit the ability of the Nigerian juvenile justice system to respond adequately to national needs. This has led to a human rights and mental health crisis in the system. Addressing the crisis will require home-grown multi-systemic approaches which take into account the strength and limitations within both the public mental health and juvenile justice systems. As a way forward, there is a need to implement some of the roadmaps which are already being suggested to address some of the limitations within these systems in Nigeria. For instance, there are pre-existing roadmaps for the establishment of diversion programmes and for separating victims from offenders in Nigeria (Atilola, 2013). In addition, strategies for incorporating mental health services into broader community healthcare systems (Gureje et al, 2015), training of more youth mental health practitioners for the country (Omigbodun \& Belfer, 2016), and task-shifting approaches for mental health services in youth correctional settings in Nigeria (Atilola, 2014) have been documented. These are important and necessary steps towards the design of context-appropriate mental health services for the youth correctional system in Nigeria.

\section{References}

Alcorn T. (2014) Rethinking mental health care for young offenders. The Lancet, 383, 1283-1284.

Atilola O. (2012) Prevalence and correlates of psychiatric disorders among residents of a juvenile remand home in Nigeria: implications for mental health service planning. Nigerian Journal of Medicine: Journal of the National Association of Resident Doctors of Nigeria, 21, 416-426.

Atilola O. (2013) Juvenile/youth justice management in Nigeria: making a case for diversion programmes. Youth Justice, 13, 3-16.

Atilola O. (2014) Different points of a continuum? Cross sectional comparison of the current and pre-contact psychosocial problems among the different categories of adolescents in institutional care in Nigeria. BMC Public Health, 12, 554.

Atilola O., Ola B., Abiri G., et al (2017) Status of mental-health services for adolescents with psychiatric morbidity in youth correctional institutions in Lagos. Journal of Child \& Adolescent Mental Health, 29(1), 63-83.

Fazel S., Doll H. \& Långström N. (2008) Mental disorders among adolescents in juvenile detention and correctional facilities: a systematic review and metaregression analysis of 25 surveys. Journal of the American Academy of Child and Adolescent Psychiatry, 47, 1010-1019.

Gureje O., Abdulmalik J., Kola L., et al (2015) Integrating mental health into primary care in Nigeria: report of a demonstration project using the mental health gap action programme intervention guide. BMC Health Services Research, 15, 242.

Kates E., Gerber E. B. \& Casey S. (2014) Prior service utilization in detained youth with mental health needs. Administration and Policy in Mental Health and Mental Health Services Research, 41, 86-92.

Omigbodun O. O. \& Belfer M. L. (2016) Building research capacity for child and adolescent mental health in Africa. Child and Adolescent Psychiatry and Mental Health, 10, 27.

Penal Reform International (2015) GLOBAL PRISON TRENDS. PRI. Available at https://www.penalreform.org/wp-content/.../ PRI-Prisons-global-trends-report-LR.pdf.

Petersen I., Lund C., Bhana A., et al (2012) A task shifting approach to primary mental health care for adults in South Africa: human resource requirements and costs for rural settings. Health Policy and Planning, 27, 42-51.

Rawal P., Romansky J., Jenuwine M., et al (2004) Racial differences in the mental health needs and service utilization of youth in the juvenile justice system. The Journal of Behavioral Health Services \& Research, 31, 242

Robertson B., Omigbodun O. \& Gaddour N. (2010) Child and adolescent psychiatry in Africa: luxury or necessity? African Journal of Psychiatry, 13, 329-331.

UN Committee on the Rights of the Child (2009) Consideration of Reports Submitted by States Parties under Article 44 of the Convention: Nigeria, pp. 123-125. CRC. 